\title{
MISE AU POINT D'UNE NOUVELLE TECHNIQUE DE CULTURE EN CELLULES SUR LAMES
}

\author{
Par Simone DREYFUS
}

Nous pensions, depuis quelque temps déjà, à modifier la méthode de cultures sur lames telle qu'elle nous avait été enseignée par notre regretté Maître, le Docteur Maurice Langeron, et par P. Guerra (1938). Le procédé original de Rivalier et Seydel, sur lames gélosées, en boîte de Pétri, avait dû être abandonné par nous, car il présentait un trop grand risque de contamination. Ces deux méthodes offraient le même inconvénient : celui de ne pouvoir suivre qu'approximativement les cultures au cours de leur développement, à l'aide d'une loupe, et au travers soit, du tube Borrel, soit de la boîte de Pétri.

Il existe également la culture cellulaire en goutte pendante, due à Van Tieghem et Le Monnier (1873), qui est une technique essentielle en mycologie, car elle permet d'observer le développement des organes de fructification au microscope et de fixer ainsi la culture en préparation définitive au moment voulu. Mais, à notre avis, le champ d'investigation est trop limité dans cette dernière méthóde, et les préparations ne peuvent subir les différentes fixations et colorations que nous avons été amenée à faire par la suite.

Nous avons été aiguillée dans nos recherches en suivant la démonstration qui nous a été faite par un médecin brésilien, le Docteur Zilberberg. Nous indiquerons, au passage, tout ce que nous avons retenu la méthode du Docteur Zilberberg.

Nous allons voir maintenant les diverses manipulations à effectuer pour appliquer cette nouvelle méthode de cultures en celluies sur lames, telle que nous l'avons mise au point :

a) Faire fondre, au bain-marie, le milieu gélosé qui doit servir à l'ensemencement des lames.

b) Préparer de petites boulettes de coton hydrophile, de la grosseur d'un petit pois moyen, et les faire bouillir dans de l'eau distillée.

c) Faire fondre de la paraffine.

d) Préparer les lames en déposant l'anneau, légèrement trempé

Ann. de Parasitologie, T. XXVI, N ${ }^{\circ} 3 .-1951$. 
dans du silicate de soude (1) ; mettre un poids sur l'anneau pour que l'adhérence soit parfaite.

e) Choisir une autre lame, la plus mince possible, bien dégraissée par les méthodes habituelles. Dessiner sur cette lame un tracé à l'encre de Chine en suivant la circonférence intérieure de l'anneau, par transparence.

f) Placer cette lame sur l'anneau, le tracé au-dessus (2). Flamber le tout, que l'on déposera, pour plus de commodité, sur un support en nickel (fig. 1).

g) Déposer à chaque extrémité de l'anneau, si celui-ci est ovale, ou le long de la paroi, si celui-ci est rond, mais toujours sur la lame du dessous, les boulettes de coton (3), légèrement essorées à l'aide d'une pince flambée.

h) Prendre du milieu gélosé à l'aide d'une pipette légèrement coudée (fig. 4), et déposer une goutte de ce milieu au centre du cercle dessiné à l'encre de Chine, mais sur l'autre face ; soulever légèrement la lame, sans la retourner, afin d'éviter toute contamination, puis étendre rapidement sur toute la surface intérieure du tracé à l'aide de la partie coudée de la pipette (fig. 4') (4).

i) Pour l'ensemencement, soulever, à nouveau, la lame et, à l'aide d'une effilure de pipette, déposer l'inoculum au centre, si l'on ne dispose que d'anneaux ronds. Pour les anneaux ovales, on peut ensemencer, soit en deux points s'il s'agit d'une culture filamenteuse, soit en une ou deux stries longitudinales lorsqu'il s'agit d'une culture levuriforme, ainsi qu'il a été décrit dans les travaux de M. Langeron et P. Guerra (1939-1940).

j) Luter à la paraffine pour faire adhérer la lame ensemencée à l'anneau. Nous prenons entre le pouce et l'index de la main gauche tout le dispositif, c'est-à-dire les deux lames avec leur anneau (fig. 2 et 3 ). Nous lutons à l'aide d'un fer à luter triangulaire, légèrement incurvé. Pour plus de commodité, on peut retourner complètement le dispositif ; les boulettes humides adhèrent parfaitement à la lame sur laquelle elles ont été déposées. On peut également luter à

(1) C'est à un travailleur du laboratoire, M. E.-M. Bastisse, maître de recherches au C.N.R.A. de Versailles, que nous devons ce procédé ; le $\mathrm{D}^{\mathrm{r}}$ Zilberberg employait une colle cellulosique qui devenait friable et qui s'est révélée d'une étanchéité imparfaite, surtout après un séjour à l'étuve. Le silicate de soude nous a donné entière satisfaction, d'autant plus qu'il permet une première stérilisation sèche au \& Poupinel ».

(2) Le $\mathrm{D}^{\mathrm{r}}$ Zilberberg plaçait le tracé face en dessous directement sur l'anneau, mais nous avons remarqué que l'encre diffusait dans les manipulations ultérieures.

(3) Cette méthode est due entièrement au D' Zilberberg.

(4) Le $\mathrm{D}^{\mathrm{r}}$ Zilberberg se servait d'un pinceau, préalablement bouilli, pour géloner les lames. J'ai préféré le procédé de la pipette coudée, qui m’a donné entière satisfaction. 
l'aide d'une pipette coudée, semblable à celle qui a servi pour géloser les lames (1) (fig. 4). Toutes ces opérations terminées, il n'y a plus qu'à déposer les cultures dans une étuve propre à leur développement, sans que les produits qui ont servi aux différentes sortes de luts en soient altérés.

F1G. 1
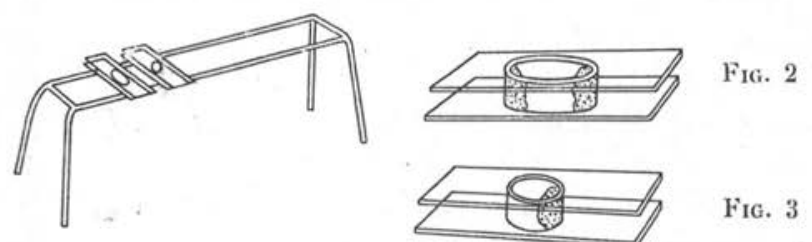

Fig. 4 '

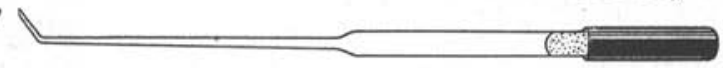

FIG. 4

\section{Conclusions}

Les chercheurs ne manqueront pas de remarquer tous les avantages qu'ils pourront tirer de cette nouvelle culture en cellule, chaque fois qu'ils auront à suivre au microscope le développement d'une culture. Cette nouvelle méthode leur permettra également de faire des ensemencements en série, qu'ils pourront arrêter à des stades différents de croissance. Nous n'avons pas besoin d'indiquer les ressources photographiques, et même cinématographiques, qu'elle peut offrir ; cela se conçoit.

Quant aux causes de contamination, elles sont pratiquement nulles. Au cours de nos très nombreuses investigations, aucune culture n'a été souillée.

\section{BiBLIOGRAPHIE}

Langeron (M.) et Guerra (P.). - Nouvelles recherches de zymologie médicale. Ann. de Parasitologie, XVI, 1938, 36-84.

Langeron (M.) et Guerra (P.). - Orientation de la filamentisation des champignons levuriformes cultivés sur lames gélosées. Ann. de Parasitologie, XVII, 6, 1939-1940, 580-589.

Van Tieghem et Le Monnier. - Recherches sur les Mucorinées. Ann. sc. nat. Bot. (5), XVII, 1873, 261-399, pl. XX-XXV.

\section{Institut de Parasitologie de la Faculté de Médecine} (Directeur : Prof. H. Galliard).

(1) Procédé suggéré par le $\mathrm{D}^{\mathrm{r}} \mathrm{H}$. Yassemi, médecin iranien, qui a travaillé dans notre laboratoire. 